\title{
28 Research Square \\ Seismic Isolation Technology for Prestressed Segmental Precast Piers
}

\section{Shuang Zou ( $\square$ zoushuang_2015@163.com )}

Guangzhou University

\section{Heisha Wenliuhan}

Guangzhou University

\section{Yanhui Liu}

Guangzhou University

\section{Zhenyu Yang}

Guangzhou University

\section{Research Article}

Keywords: Prestressed segmental precast pier, seismic performance, full-scale in-situ loading test, seismic isolation device, optimal designPrestressed segmental precast pier, seismic performance, fullscale in-situ loading test, seismic isolation device, optimal design

Posted Date: August 6th, 2021

DOl: https://doi.org/10.21203/rs.3.rs-757152/v1

License: (c) (i) This work is licensed under a Creative Commons Attribution 4.0 International License. Read Full License 


\section{Abstract}

Due to its poor energy dissipation capacity, the application of prestressed segmental precast piers in bridge engineering in areas with medium- and high-intensity seismic activity is limited. This study proposes the use of a functional separation seismic isolation device (FSID) that acts as an external replaceable energy dissipation device to increase the energy dissipation capacity of prestressed segmental precast piers. Full-scale in-situ load tests on an actual prestressed segmental precast pier were carried out to clarify the seismic performance of this kind of pier. Based on the results of the tests and further analysis, an optimal design of the functional separation seismic isolation device is obtained by incorporating the optimal mechanical performance parameters of the device. The FSID proposed in this study can meet the seismic performance requirements of prestressed segmental precast piers under different levels of earthquakes.

\section{Introduction}

A pressed segmental precast pier is constructed by applying post-tensioned prestress to focus the nonlinear rotation of the precast pier under seismic action mainly on the rocking joint (Wang et al. 2020; Wang et al. 2018) to ensure that the prefabricated components remain elastic and that the residual deformation is small after loading (Li et al. 2019; Chou and Chen 2006; Sun et al. 2016). However, due to its poor energy dissipation capacity and large displacement demand under the action of earthquakes, its application in bridge engineering in areas with medium and high seismic activity is limited (Yamashita and Sanders 2009; Ge et al. 2017; Zhang et al. 2019; Chou and Chen 2006; Ou et al. 2009).

To solve the problem of both the poor energy dissipation capacity and the large displacement demand, external replaceable energy dissipation devices are used in prestressed segmental precast piers (Marriott et al. 2009; Marriott et al. 2011). Chou (Chou and Chen 2006) proposed a method of energy dissipation in which concrete segments are restrained by circular tubes and connected by post-tensioned tendons. The low cycle reciprocating test shows that the proposed energy dissipation method can ensure that the specimen has good energy dissipation ability. Marriott (Marriott et al. 2011; Sarti et al. 2016; Andissheh et al. 2018; ElGawady et al. 2010) proposed a method to improve the energy dissipation capacity of prestressed segmental precast piers by using energy dissipating steel bars wrapped with steel pipes. The feasibility of this scheme was verified by quasi-static tests. The hysteretic behavior of energy dissipating steel bars was further studied by Marriott by repeated tension and compression tests based on the OPENSEES model. Elgawady (EIGawady et al. 2010; ElGawady and Sha'lan 2010; Moustafa A and ELGawady 2018) used bolts to fix angle steel between the cap beam and the bearing platform to achieve energy consumption by a precast double-column pier under the action of earthquakes. In addition, some scholars have proposed and studied, through numerical models, the addition of buckling restrained braces between precast double columns. Most of the above studies focused on adding an external energy dissipation device at the bottom of the pier column because it is the most stressed part under horizontal seismic action to improve the seismic performance of the pier by enabling it to consume excessive seismic action at the bottom of the column (Dong et al. 2017; Wang et al. 2019). However, the 
energy dissipation effect of energy dissipation devices installed at the base of columns is limited. There are two reasons for this. First, the use of energy dissipation devices does not reduce the total energy input. Second, the energy dissipation device needs a certain amount of deformation (displacement, angle) to occur at the bottom of the column to properly dissipate energy.

To address the above problems, this paper proposes the placing of a functional separation seismic isolation device (FSID) between the pier cap beam and the upper beam body. Through deformation, the FSID can reduce and consume the total seismic energy input into the bridge pier, and adopts the form of function separation, which makes it easy to design and control. To study the seismic response control effect of the FSID on a prestressed segmental precast pier, a full-scale load test of the prestressed segmental precast pier was performed. Based on the results of this test and the seismic performance requirements of prestressed segmental precast piers under different levels of earthquake magnitudes, an optimized FSID design is proposed.

\section{Full-scale Loading Tests}

\subsection{Specimen design and construction}

Full-scale loading tests were carried out on a prestressed segmental precast pier modeled after that used in the Hetian Ruoqiang railway. The Hetian Ruoqiang railway is located in Hetian city in the south of the Xinjiang Uygur Autonomous Region. Figure 1 shows the geometry and section details of the prestressed segmental precast pier. The mechanical properties of the materials used to form the prestressed segmental precast pier specimens are listed in Table 1. The prestressed segmental precast pier is divided into three parts: the cap beam, the pier body segments, and the bearing platform. Each segment of the pier body is made separately, and then they are assembled to create the bridge pier when the concrete strength reaches the design strength. 12 high strength and low relaxation self-anchored prestressed tendons with a diameter of $15.2 \mathrm{~mm}$ were used to form the prestressed system. The standard tensile strength of each prestressed tendon is $f_{\mathrm{pk}}=1,860 \mathrm{MPa}$. The tension control stress at the anchor is 1,116 $\mathrm{MPa}$.

The construction procedure of the prestressed segmental precast pier is as follows:

(1) The metal bellows were embedded in the bearing platform, the column, and the cap beam, forming the tendon duct during the prefabricating process.

(2) The pier column was placed in position (Fig. 2 (a)).

(3) The cap beam was placed in position (Fig. 2 (b)).

(4) The tendons pass through the metal bellows from the top of the cap beam to the bottom of the column. After self-anchoring the prestressed tendons at the bottom of the column, the prestressed tendons were tensioned at the top of the bent cap. The tension stress of each prestressed tendon was 
controlled at 1,116 MPa. After the tension stress became stable, the top of the prestressed tendons was anchored (Fig. 2 (c)).

(5) Backfill concrete mortar was poured into the reserved grooves of the bearing platform. Concrete mortar and grout were poured in from the top of the bent cap to the bottom, sealing the metal bellows, preventing the corrosion of the tendons, and ensuring the synchronous deformation of the tendons and each segment of the pier (Fig. 2 (d)).

Table 1. Properties of the prestressed segmental precast pier sample

\begin{tabular}{|c|c|}
\hline specimen & Segmental columns \\
\hline \multirow[t]{2}{*}{ Prestressed tendon } & Material: 12 tendons of diameter $15.2 \mathrm{~mm}$ \\
\hline & Yielding stress (MPa): 1890; Initial stress (MPa): 1,116 \\
\hline \multirow[t]{2}{*}{$\begin{array}{l}\text { Longitudinal } \\
\text { reinforcement bar }\end{array}$} & $\begin{array}{l}\text { Material: hot-rolled ribbed bars (HRB) with a diameter of } 12 \mathrm{~mm} \text {, } \\
\text { accounting for a reinforcement ratio of approximately } 1.0 \% \text {. }\end{array}$ \\
\hline & Yielding stress (MPa): 410 \\
\hline \multirow{2}{*}{$\begin{array}{l}\text { Transverse } \\
\text { reinforcement bar } \\
\text { Stirrup spacing: } 100 \\
\text { mm (Encrypted area); }\end{array}$} & Material: $12 \mathrm{~mm}$ diameter \\
\hline & Yielding stress (MPa): 410 \\
\hline \multicolumn{2}{|l|}{$\begin{array}{l}\text { Stirrup spacing: } 150 \\
\mathrm{~mm}\end{array}$} \\
\hline \multirow[t]{2}{*}{ Strength of concrete } & $50 \mathrm{MPa}$ \\
\hline & $\begin{array}{l}\text { The concrete grade is } \mathrm{C} 50 \text { with the standard value of cubic compressive } \\
\text { strength of } 50 \mathrm{MPa}\end{array}$ \\
\hline
\end{tabular}

\subsection{Test overview}

\subsubsection{Loading system}

A vertical reaction frame was set up to impose a constant vertical load of 2,000 $\mathrm{kN}$ on the top of the bent cap to simulate the dead load of a bridge superstructure. As shown in Fig. 3, the steel beam of the reaction frame, placed above the cap beam, is connected to the cushion cap with $32 \mathrm{D} 32 \mathrm{~mm}$ thread steel bars using anchors embedded in the cushion cap. Thus, the loading steel beam, steel bars, and cushion cap form the vertical reaction frame. Four jacks were set between the loading steel beam and the pier bent cap. The axial load, applied at the top of the bent cap, was maintained throughout the experiment to simulate the permanent load acting on the top of the pier. To reduce the influence of the vertical reaction frame on the horizontal displacement of the pier, two metal friction bearings with very small friction coefficients were set between the jacks and the loading steel beam, as shown in Fig. 3. 
A horizontal load was applied at the bent cap through a horizontal reaction frame. As shown in Fig. 3 , this frame is a $15 \mathrm{~m}$ high steel frame with very high stiffness. Sufficient concrete blocks were placed at the bottom of the horizontal reaction frame to ensure that it did not overturn during the loading procedure. The bent cap was connected to the horizontal reaction frame with a prestressed tendon, which passed through a $15 \mathrm{~cm}$ diameter hole at the center of the bent cap and was anchored at the side of the cap, while its other end passed through the jack, which was installed on the horizontal reaction frame. The horizontal displacement was imposed at the bent cap through the jack.

\subsubsection{Load programs}

The horizontal displacement was applied step by step through the jack installed on the horizontal reaction frame, as shown in Fig. 3. The imposed displacement at the cap beam was gradually increased from $5 \mathrm{~mm}$ to $130 \mathrm{~mm}$ at an increment of $5 \mathrm{~mm}$. During the test, a laser displacement sensor measured the relative displacement between the cap beam and the top surface of the bearing platform.

\subsection{Load-displacement curves}

The relationship between the horizontal load and the horizontal displacement at the top of the pier is plotted in Fig. 4. Based on the relationship curve, the parameters of the main characteristic points (yield point, peak point, and limit point) were obtained as shown in Table 3. The yield point was determined by the park method (Shim et al. 2008). It can be noted that the maximum bearing capacity is $1,479 \mathrm{kN}$, and the equivalent yield stiffness is $22,020 \mathrm{kN} / \mathrm{m}$.

Table 2. Key values of the load-displacement curves from the experiment

\begin{tabular}{|llllll|}
\hline \multicolumn{2}{l}{ First crack } & \multicolumn{2}{l}{ Equivalent yield point } & \multicolumn{2}{l|}{ Maximum horizontal force } \\
\hline Force & Displacement & Force & Displacement & Force & Displacement \\
{$[\mathrm{kN}]$} & {$[\mathrm{mm}]$} & $F_{y} / \mathrm{kN}$ & $\delta_{y} / \mathrm{mm}$ & $F_{u} / \mathrm{kN}$ & $\delta_{u} / \mathrm{mm}$ \\
\hline 904 & 31.2 & 1090 & 49.5 & 1479 & 122.6 \\
\hline
\end{tabular}

\section{Overview Of Fsid}

The prestressed segmental precast pier has a characteristic of restorability. However, its hysteretic energy dissipation capacity is weak, and it may undergo brittle failure. The purpose of this study is to increase the energy consumption capacity of a bridge system with prestressed segmental precast piers and improve its seismic performance using a combination of different energy dissipation devices.

\subsection{Structure of the FSID}

A functional separation seismic isolation device is proposed to improve the energy dissipation and deformation capacity of bridges with prestressed segmental precast piers. The isolation device (Fig. 5) is composed of two vertical friction sliding bearings placed vertically and two high damping laminated 
rubber bearings placed horizontally. The friction sliding bearing (Fig. 5) placed vertically bears all the vertical load and maintains stability through shear keys and friction. Through the friction sliding of the sliding interface, the seismic energy is isolated and input to the upper beam body, and the motion period of the beam body is prolonged to achieve the isolation of the seismic energy. The high damping laminated rubber bearing is placed horizontally so that it does not bear the vertical load and consumes earthquake energy through shear deformation.

\subsection{Working mechanism}

Based on whether the dowel in the friction sliding bearing is sheared or not during earthquake activity, the isolation device can be divided into three working stages.

Step 1: normal use stage. Frequent earthquakes with smaller magnitudes are more likely to occur resulting in the bridge being in a normal use stage. The horizontal seismic action does not cause the shear key to reach its ultimate bearing capacity in the friction sliding bearing, and the shear key remains elastic at this stage; this is to improve the horizontal bearing capacity of the bearing system and ensure that longitudinal sliding of the main beam does not occur. In this stage, the FSID is not in active use. Under the action of a one-way earthquake, the restoring force model of the FSID at this stage is shown in Fig. 7 (a), and $P$ is the ultimate horizontal bearing capacity of the shear key.

Step 2: seismic isolation stage. The magnitude of fortification intensity earthquakes is usually larger. During their occurrence, it is necessary to ensure that the structure has clear energy-consuming characteristics. In this stage, the shear key will be destroyed to ensure the proper sliding of the friction bearing and the shear deformation of the high damping rubber bearing to fully dissipate the seismic energy and reduce excessive damage to the superstructure. Under the action of a unidirectional earthquake, the restoring force model of the FSID at this stage is shown in Fig. 7 (b), in which $\mu_{1}$ is the friction coefficient; $M$ is the vertical load; $K_{1}$ is the initial stiffness of the high damping laminated rubber bearing; $K_{2}$ is the post yield stiffness; $f_{y}$ is the yield load.

Stage 3: displacement limiting stage. Rarely, very high magnitude earthquakes occur. When one does occur, the bridge needs a limiting device to control the excessive horizontal displacement, and collisions between the upper beams must be avoided. At this stage, the friction coefficient will be adjusted to balance the friction force of the friction bearing and the restoring force of the high damping rubber bearing to optimize the displacement control function. Under the action of a unidirectional earthquake, the restoring force model of the FSID at this stage is shown in Fig. 7 (c), in which $\mu_{2}$ is the friction coefficient.

\subsection{Advantages of the FSID}

The functional separation seismic isolation device separates the vertical bearing function from the horizontal displacement control function, and the normal use function from the seismic isolation function. Some of the advantages of the FSID include that the friction sliding bearing has a large vertical bearing capacity, the FSID shows good hysteretic energy dissipation, and the high damping laminated 
rubber bearing has a strong self-reset capability. Since the friction sliding bearing and the high damping laminated rubber bearing are uncoupled, the energy dissipation device has the characteristics of a clear force transmission path, a single function for each component, and it is easy to design and control. The FSID is a multi-stage working mechanism to achieve a performance-based seismic design of prestressed segmental precast piers (Zou et al. 2019).

\section{Analysis Of The Fsid}

\subsection{Characteristics of the analysis model}

The elastic design method is usually adopted in the seismic design of prestressed segmental precast piers to prevent plastic behavior (Li et al. 2008; Wang et al. 2020). Moreover, all the deformation and energy dissipation is mainly concentrated in the isolation devices after they are added. Therefore, the pier of the isolation device in this study is simplified into a single particle model as shown in Fig. $8 . \mathrm{M}$ is the vertical load on the isolation bearing.

\subsection{Input ground motion}

Table 3 shows the input ground motions. The ground motion in the table is divided into five levels for consideration. In the following discussion, $\mathrm{g}$ is the acceleration of gravity, $\mathrm{g}=9.8 \mathrm{~m} / \mathrm{s}^{2}$. The Newmark $\beta$ ( $\beta$ $=0.25$ ) is used to conduct a time history analysis for all the input ground motions, and an estimation is made for the maximum response of each level of the input ground motion. 
Table 4

Input ground motions

\begin{tabular}{|c|c|c|c|c|c|c|c|}
\hline \multicolumn{2}{|c|}{ Input ground motion } & \multirow[t]{3}{*}{ Notation } & \multicolumn{5}{|c|}{ PGA [g] } \\
\hline & & & \multirow{2}{*}{$\begin{array}{l}\text { Small } \\
\text { Lv.1 }\end{array}$} & \multicolumn{3}{|c|}{$\begin{array}{l}\text { Moderate and } \\
\text { large }\end{array}$} & \multirow{2}{*}{$\begin{array}{l}\text { Rare } \\
\text { Lv.5 }\end{array}$} \\
\hline & & & & Lv.2 & Lv.3 & Lv.4 & \\
\hline \multirow[t]{4}{*}{ Observed } & $\begin{array}{l}\text { NS component of imperial Valley, } \\
\text { USA, } 1979\end{array}$ & EIC-NS & 0.1 & 0.2 & 0.3 & 0.4 & 0.5 \\
\hline & $\begin{array}{l}\text { EW component of Hachinohe, } \\
\text { Tokachi, Japan, } 1968\end{array}$ & HCN-EW & 0.1 & 0.2 & 0.3 & 0.4 & 0.5 \\
\hline & NS component of Kobe, Japan, 1995 & KOB-NS & 0.1 & 0.2 & 0.3 & 0.4 & 0.5 \\
\hline & $\begin{array}{l}\text { EW component of Kern County, USA, } \\
1952\end{array}$ & TAF-EW & 0.1 & 0.2 & 0.3 & 0.4 & 0.5 \\
\hline \multirow[t]{2}{*}{ Artificial } & $\begin{array}{l}\text { Notice earthquake made by NS } \\
\text { Component phase of Kobe }\end{array}$ & KOB-MA & 0.1 & 0.2 & 0.3 & 0.4 & 0.5 \\
\hline & $\begin{array}{l}\text { Notice earthquake made by NS } \\
\text { Component phase Tohoku university, } \\
\text { Miyagi, Japan, } 2011\end{array}$ & THU-NS & 0.1 & 0.2 & 0.3 & 0.4 & 0.5 \\
\hline
\end{tabular}

\subsection{Design variables and design method}

Based on the analysis model shown in Fig. 8, we performed an investigation to identify the optimal mechanical parameters of the functional separation isolation device. In this experiment, the FSID is required to play different control roles according to different input ground motion levels. By analyzing the seismic performance requirements of piers under different levels of earthquakes, we obtained the optimal mechanical parameters of the FSID. In this study, the sequential quadratic programming (SQP) method was used to optimize the damper parameters (Zou et al. 2021; Zou et al. 2020).

\subsubsection{1st optimum design}

In the 1st optimum design, the FSID was used as an energy dissipation device under Lv.1 Lv.4 level ground motions. The optimization problem is shown in Table 5. 
Table 5

The 1 st optimum design

\begin{tabular}{|ll|}
\hline Find & $K_{1} \square f_{\mathbf{y}} \square K_{2} \square \mu_{1}$ \\
\hline To minimize & $A_{\max }$ \\
\hline Subject to & (1) $D_{\max } \leq 0.15 \mathrm{~m}$ \\
& (2) $F_{L V .1} \leqslant \sum F_{u}+F_{f} \leqslant F_{y}$ \\
& (2) $D_{\mathrm{c}} \leq 0.05 \mathrm{~m}$ \\
\hline
\end{tabular}

Optimization parameters

The elastic stiffness $K_{1}$, yield load $F_{y}$, and post yield stiffness $K_{2}$ of the high damping laminated rubber bearing and friction coefficient $\mu_{1}$ were considered as the parameters to be optimized.

Objective function

Under the Lv.1-Lv.4 ground motions, to keep the pier elastic at all times, the optimal mechanical parameters of the FSID were obtained to minimize the maximum seismic response acceleration of the capping beam.

(3) Constraints

(a) Considering the safety and stability of the bridge and the limit of the expansion joint, the maximum displacement of the pier cannot exceed the limit value. In this project, the limit value was set as $0.15 \mathrm{~m}$. (b) Under a Lv. 1 horizontal earthquake, the FSID is in working stage 1, which can give full play to the seismic performance of the pier itself. When a Lv. 2 earthquake occurs, the FSID enters the second working stage and performs seismic isolation. In addition, under a horizontal earthquake action of Lv.2 Lv.4, the pier columns always remain in an elastic working state, and the maximum horizontal force of the FSID should not exceed the horizontal yield shear force of the pier column. Therefore, the ultimate horizontal bearing capacity $F_{\mathrm{f}}$ can be calculated by the following formula.

$F_{L v .1} \leq \sum F_{u \text {-dowel }}+F_{f} \leq \min \left\{F_{L v 2,}, F_{y}\right\}$

Where: $F_{\mathrm{Lv} .1}$ and $F_{\mathrm{Lv} .2}$ are the maximum horizontal force on the cap beam under an earthquake action of Lv. 1 and Lv. 2, respectively; $\sum F_{u \text {-dowel }}$ is the total bearing capacity of the dowels; $F_{f}$ is the total horizontal force of the FSID; $F_{\mathrm{y}}$ is the yield shear force of the pier column. According to the full-scale test results, the $F_{\mathrm{y}}$ is $1,090 \mathrm{KN}$ (Fig. 4).

(c) It is necessary to control the residual deformation of the FSID to improve the repairability of the bridge after an earthquake and avoid collision damage to the beam caused by aftershocks.

\subsubsection{2nd optimum design}


The FSID is considered as a limiting device to control the excessive displacement of the FSID under Lv.5 earthquakes and prevent collision damage to the cap beam. The optimization problem is shown in Table 6.

(1) Optimization parameters

We performed analysis to obtain the optimal value of the friction coefficient $\mu_{2}$ of the friction sliding bearing.

(2) Objective function

Under Lv. 5 ground motions, to ensure that the pier does not reach the ultimate bearing capacity, the optimal FSID mechanical parameters were obtained to minimize the maximum seismic response displacement of the cap beam.

(3) Constraints

The maximum horizontal shear force on the cap beam must not exceed the ultimate bearing capacity of the pier column under Lv. 5 earthquakes. The horizontal ultimate bearing capacity $F$ can be calculated by the following formula, where: $F_{\mathrm{u}}$ is the ultimate bearing capacity of the pier column.

$$
F_{f} \leqslant F_{u}
$$

2

Table 6

The 2nd optimum design

\begin{tabular}{|ll|}
\hline Find & $\mu_{2}$ \\
\hline To minimize & $D_{\max }$ \\
\hline Subject to & $F_{f} \leqslant F_{u}$ \\
\hline
\end{tabular}

\subsection{Analysis results}

Table 7 shows the optimal FSID design variables obtained in this study.

Table 7

Optimized design variables

\begin{tabular}{|lllll|}
\hline$K_{1} / \mathrm{kN} / \mathrm{m}$ & $\boldsymbol{f}_{\boldsymbol{y}} / \mathrm{kN}$ & $\kappa_{2} / \mathrm{kN} / \mathrm{m}$ & $\mu_{1}$ & $\mu_{2}$ \\
\hline 28130 & 641 & 1349 & 0.107 & 0.088 \\
\hline
\end{tabular}




\subsubsection{Maximum responses}

Figure 9 shows the maximum responses of the beam. FSID (only $\mu_{1}$ ) are the maximum responses obtained when the high damping laminated rubber bearing and the friction sliding bearing with only one friction coefficient $\mu_{1}$ are adopted. FSID $\left(\mu_{1}+\mu_{2}\right)$ are the maximum responses obtained when the high damping laminated rubber bearing and friction sliding bearing with two friction coefficients are adopted. The without FSID values are the maximum responses when the pier and beam are consolidated.

In the without FSID case, the maximum horizontal shear force on the cap beam reaches the ultimate bearing capacity of the column, and the pier is damaged. Therefore, the maximum seismic response under Lv. 3 and Lv. 4 earthquakes is not drawn in Fig. 9.

In the 1st optimization, under Lv. $1 \sim$ Lv.4 ground motions, in the case of with FSID (only $\mu_{1}$ ) and with FSID $\left(\mu_{1}+\mu_{2}\right)$, the maximum seismic response acceleration and the maximum horizontal shear force of the cap beam are controlled within the elastic working requirements. The maximum horizontal displacement of the upper beam is amplified, but it is still controlled within the constraint range. This shows that the FSID between the pier and the upper beam acts as an effective seismic isolation device and ensures that the fabricated pier always remains in the elastic working state.

In the 2nd optimal design, under Lv. 5 ground motions, in the case of with FSID $\left(\mu_{1}+\mu_{2}\right)$, due to the use of the second friction coefficient $\mu_{2}$, the horizontal displacement of the beam is further reduced (as compared with the case of with FSID (only $\left.\mu_{1}\right)$ ) to ensure that the maximum horizontal force on the pier does not exceed the ultimate bearing capacity. This shows that under rare high-magnitude earthquakes, the FSID plays a controlling role as a limiting device between the pier and the upper beam.

\subsubsection{Hysteresis loops}

Figure 10 shows the hysteresis loops of the FSID under each level under TAF-EW earthquakes. The figure shows that the FSID functioned as designed. Under Lv. 1 earthquakes, the FSID is always in stage 1. Under LV.2- Lv.4 earthquakes, the FSID enters stage 2, and the hysteresis curve becomes fuller with the increase in the peak value of the input acceleration. Under Lv. 5 earthquakes, the pier is always in an elastic working state. The hysteresis curve of the FSID in Fig. 10 is fuller, and it shows obvious three-stage working characteristics.

\subsubsection{Time history}

Figure 11 shows the time history around the maximum responses for the Lv. 5 input ground motions of the TAF-EW earthquakes. At $3.4 \mathrm{~s}$, the pier specimen without the FSID became damaged. In the with FSID case, the maximum displacement of the FSID is less than $0.15 \mathrm{~m}$ before $3.8 \mathrm{~s}$, and the relative slip of the friction damper is always at the area of the friction coefficient $\mu_{1}$. Therefore, the seismic response of the pier is the same in both cases (with FSID (only $\mu_{1}$ ) and with FSID $\left(\mu_{1}+\mu_{2}\right)$ ). After $3.8 \mathrm{~s}$, the maximum 
displacement of the FSID exceeds $0.15 \mathrm{~m}$ several times, and the relative slip of the friction damper reaches the area of the friction coefficient $\mu_{2}$. It can be seen that when the relative sliding reaches the area of the friction coefficient $\mu_{2}$, the friction force of the friction bearing decreases, and the restoring force of the high damping rubber bearing comes into play so that the excessive displacement on one side is restored. Therefore, the maximum displacement and residual displacement in the with FSID $\left(\mu_{1}+\mu_{2}\right)$ case is reduced as compared to the FSID (only $\mu_{1}$ ) case.

\section{Conclusions}

In this study, full-scale in-situ load tests were conducted on a prestressed segmental precast pier to determine the seismic performance of the pier. Based on the test results, a functional separation seismic isolation device is proposed to improve the energy dissipation and deformation capacity of prestressed segmental precast piers. The optimal performance parameters of the functional separation seismic isolation device are identified through an optimization design method. The following conclusions are obtained.

(1) Through in-situ load tests, the load and the corresponding displacement of the key points in the loaddisplacement curve were obtained.

(2) From the analytical results, it is clear that the proposed design method can provide an optimal solution that satisfies the multiple design criteria corresponding to the each level of the input ground motion.

(3) The FSID was effectively activated according to the input ground motions, and it shows obvious threestage working characteristics. The prestressed segmental precast pier with mixed connection using the FSID always remains in an elastic working state. The FSID serves as an effective seismic isolation device between the pier column and the upper beam during moderate and large earthquakes. The FSID also acts as an effective limiting device to control the excessive displacement between the bridge pier and the upper beam under rare high-magnitude earthquakes. The multi-stage working mechanism of the FSID can help to achieve the performance-based seismic design of prestressed segmental precast piers.

\section{Declarations}

\section{Acknowledgments}

This research is funded by the China Railway Corporation (No. 2018G034 and No. 2018G035). Their support is gratefully acknowledged.

\section{Conflict of interest statement}

The authors declare no conflict of interest in preparing this article. 


\section{References}

1. Wang Z, Wang JQ, Zhao GT, Zhang J (2020) Modeling seismic behavior of precast segmental UHPC bridge columns in a simplified method. Bull Earthq Eng, 18: 3317-3349.https://doi.org/10.1007/ s10518-020-00817-z

2. Wang JQ, Wang Z, Tang YC, Liu TX, Zhang J (2018) Cyclic loading test of self-centering precast segmental unbonded posttensioned UHPFRC bridge columns. Bull Earthq Eng 16:5227-5255. https://doi.org/10.1007/s10518-018-0331-y

3. Li C, Bi KM, Hao H, Zhang XH, Tin DV (2019) Cyclic test and numerical study of precast segmental concrete columns with BFRP and TEED. Bull Earthq Eng, 17: 3475-3494. https://doi.org/10.1007 /s10518-019-00597-1

4. Chou CC, Chen YC (2006) Cyclic tests of post-tensioned precast CFT segmental bridge columns with unbonded strands. Earthquake Engineering Structural Dynamics 35:159-175.

https://doi.org/10.1002/eqe.512

5. Sun Z, Wang D, Bi K, Si B (2016) Experimental and numerical investigations on the seismic behavior of bridge piers with vertical unbonded prestressing strands. Bull Earthq Eng, 14: 501-527. https:// doi.org/10.1007/s10518-015-9840-0

6. Yamashita R, Sanders DH (2009) Seismic performance of precast unbonded prestressed concrete columns. ACI Structral Journal 106(6):821-830

7. Ge JP, Yan XF, Wang ZQ (2017) Seismic performance analysis of two-segment bridge columns with prestressing bars. Journal of Railway Science Engineering 14(11):2390-2398

8. Zhang YY, Wu G, Dias-da-Costa D (2019) Cyclic loading tests and analyses of posttensioned concrete bridge columns combining cast-in-place and precast segments. Bull Earthq Eng 17:61416163. https://doi.org/10.1007/s10518-019-00714-0

9. Ou YC, Wang PH, Tsai MS, Chang KC, Lee GC (2009) Large-scale experimental study of precast segmental unbonded posttensioned concrete bridge columns for seismic regions. Journal of Structure Engineering 136:255-264. https://doi.org/10.1061/(ASCE)ST.1943-541X.0000110

10. Marriott D, Pampanin S, Palermo A (2009) Quasi-static and pseudo-dynamic testing of unbonded post-tensioned rocking bridge pies with exterrnal replaceable disspaters. Earthquake Engineering Structural Dynamics 38(3):331-354. https://doi.org/10.1002/eqe.857

11. Marriott D, Pampanin S, Palermo A (2011) Biaxial testing of unbonded post-tensioned rocking bridge piers with external replacable dissipaters. Earhquake Engineering Structural Dynamics, 40(15): 1723-1741. https:// doi.org/10.1002/eqe.1112

12. Sarti F, Palermo A, Pampanin S (2016) Fuse-type external replaceable dissipaters: Experimental program and numerical modeling [J]. Journal of Structural Engineering 2016, 142(12): 04016134. https://doi.org/ 10.1061/(ASCE)ST.1943-541X.0001606

13. Andissheh K, Liu R, Palermo A et al (2018) Cyclic behavior of conrroded fuse-type dissipaters for posttensioned rocking bridges. J Bridge Engineering 23(4):04018008. https://doi.org/10.1061/ 
(ASCE)BE.1943-5592.0001197

14. ElGawady M, Booker AJ, Dawood HM (2010) Seismic behavior of posttensioned concrete-filled fiber tubers. J Compos Constr 14(5):616-628. https://doi.org/10.1061/(ASCE)CC.1943-5614. 0000107

15. ElGawady MA, Sha'lan A (2010) Seismic behavior of self-centering preccast segmental bridge bents [J]. J Bridge Engineering 16(3):328-339. https://doi.org/10.1061/(ASCE)BE.1943-5592.0000174

16. Moustafa A, ELGawady MA (2018) Shaking table testing of segmental hollow-core FRP-concretesteel bridge columns. J Bridge Engineering 23(5):04018020.

https://doi.org/10.1061/(ASCE)BE.1943-5592. 0001238

17. Dong HH, Du XL, Han Q et al (2017) Performance of an innovative self-centering bucking restrained brace for mitigating seismic responses of bridge structures with double-column piers. Eng Struct 148:47-62. https://doi.org/10.1016/j.engstruct.2017.06.011

18. Wang JQ, Wang Z, Gao YF, Zhu JZ (2019) Review on seismic behavior of precast assembly piers: new material, mew concept, new application. Eng Mech 36(3):1-23

19. Shim CS, Chung $\mathrm{CH}$, Kim HH (2008) Experimental evaluation of seismic performance of precast segmental bridge pies with a circular solid section. Eng Struct, 30(12): 3782-3792. https://doi.org/10.1016/ j.engstruct.2008.07.005

20. Zou S, Wenliuhan HS, Zhou FL (2019) Shaking table test of a high-speed railway bridge with a new isolation System. Eng Struct 196:109315. https://doi.org/10.1016/j.engstruct.2019.109315

21. Li C, Hao H, Bi KM (2008) Numerical study on the seismic performance of precast segmental concrete columns under cyclic loading. Eng Struct, 30(12): 3782-3792.

https://doi.org/10.1016/j.engstruct. 2017.06.062

22. Wang Z, Wang JQ, Zhao GT, Zhang J (2020) Modeling seismic behavior of precast segmental UHPC bridge columns in a simplified method. Bull Earthq Eng, 18: 3317-3349. https://doi.org/10.1007 /s10518-020-00817-z

23. Zou S, Wenliuhan HS, Inoue N (2021) Assessment of seismic performance of an isolated structure equipped with a friction damper with coupling mechanism and oil damper. Advances in Strcutural Engineering, 24(8): 1599-1613. https://doi.org/10.1177/ 1369433220981657

24. Zou S, Wenliusha HS, Tan P (2020) Performance-based dynamic optimal design for isolated structures with multiple-coupling friction dampers. Advances in Strcutural Engineering, 23(10): 2149-2162. https://doi.org/ 10.1177/1369433220908110

\section{Figures}




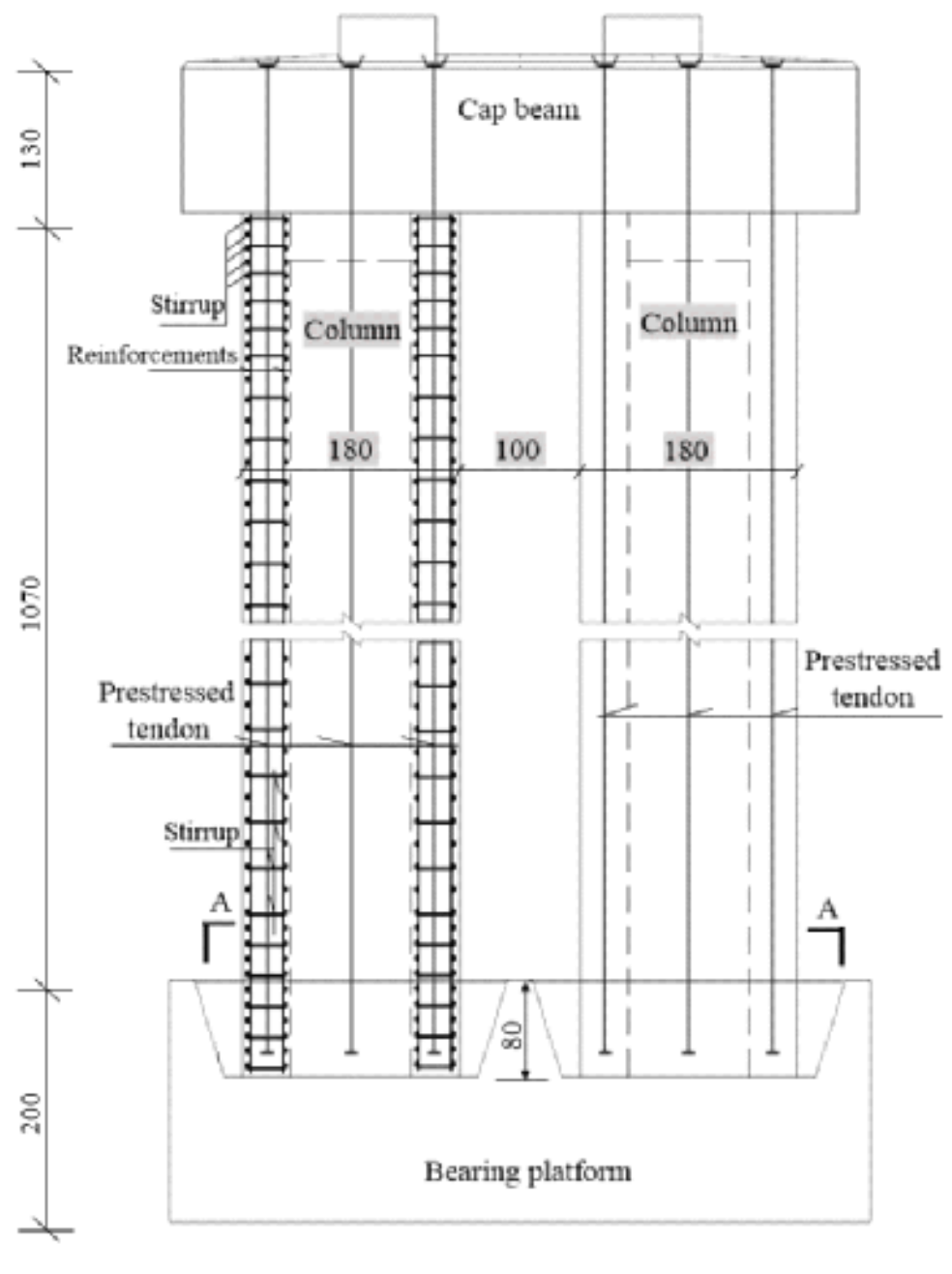

(a)

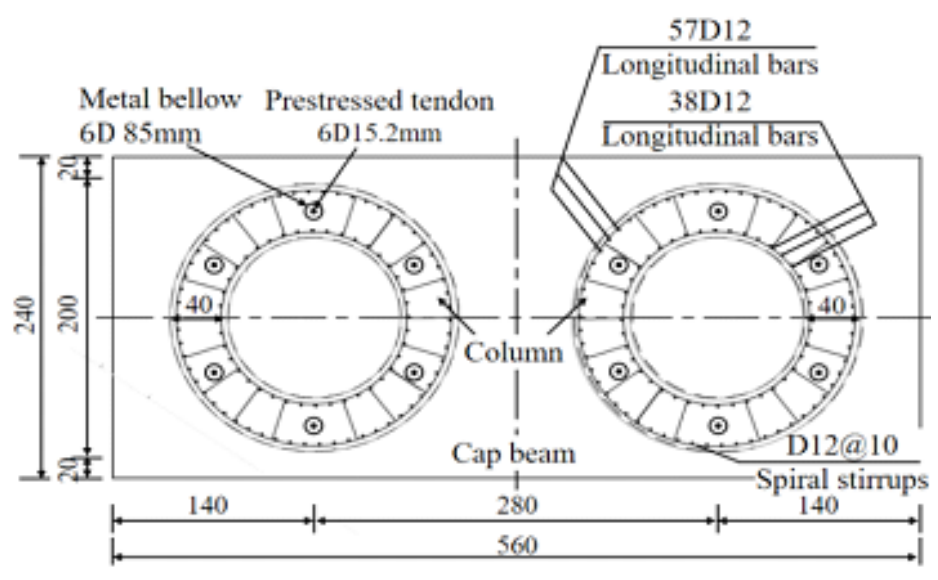

Section A-A

(b)

\section{Figure 1}

Overview of the prestressed segmental precast pier prototype $(\mathrm{cm})$ 


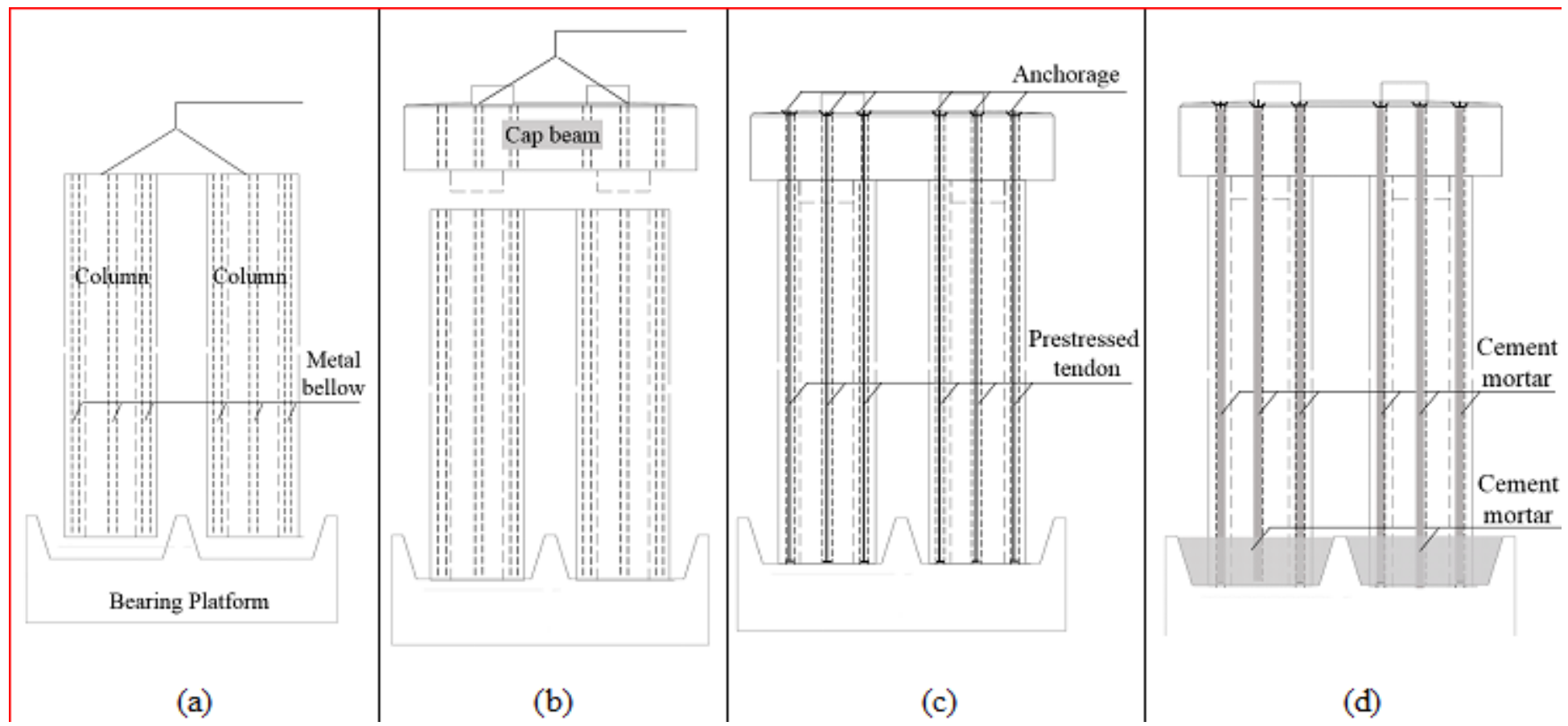

Figure 2

Construction process of the prestressed segmental precast pier specimen

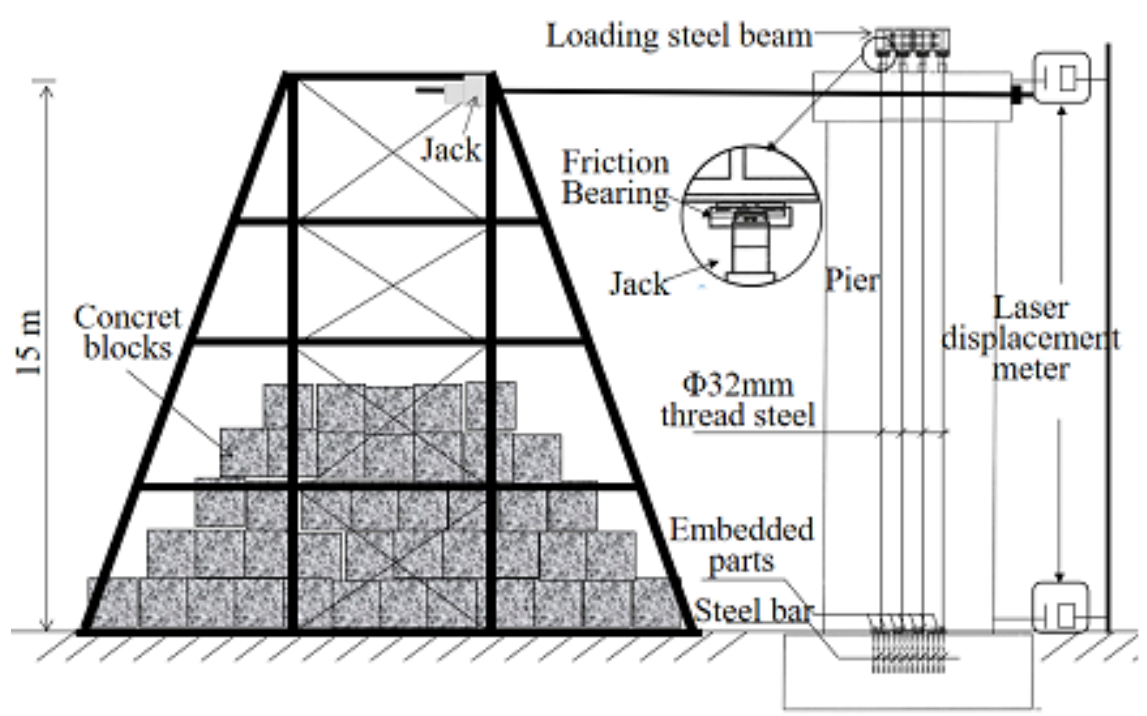

Figure 3

Loading equipment 


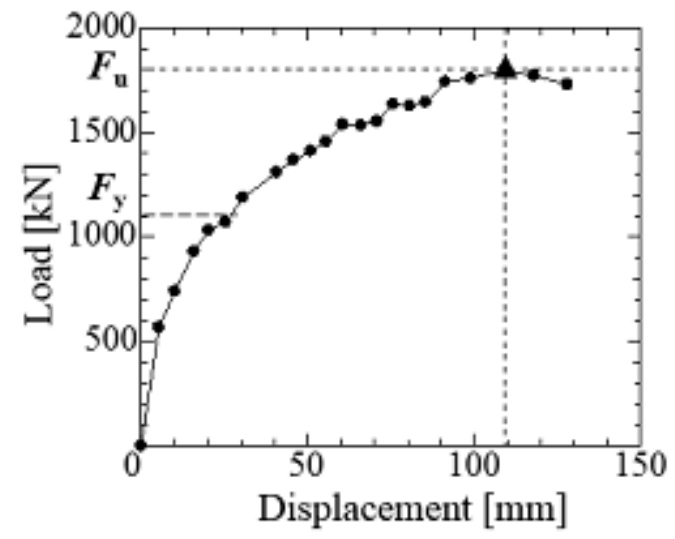

Figure 4

Load-displacement curve

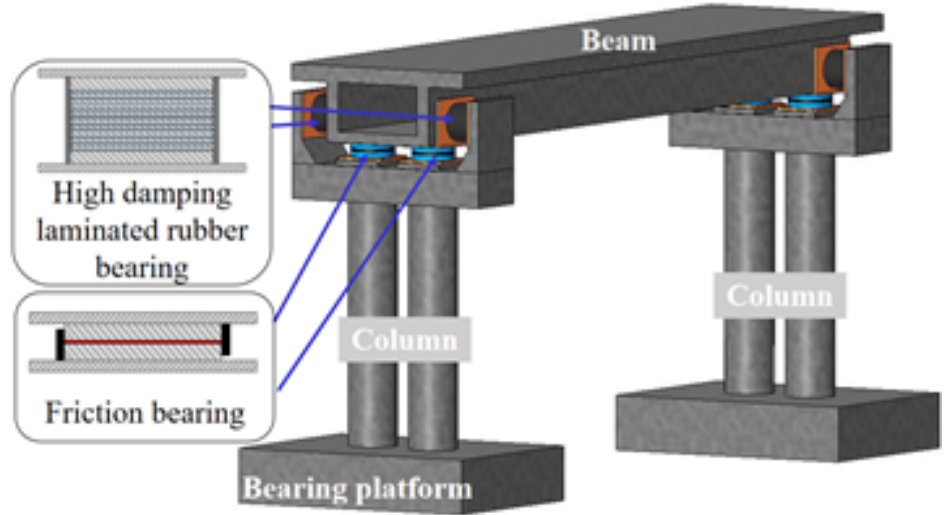

Figure 5

Schematic diagram of the prestressed segmental precast pier bridge with the FSID

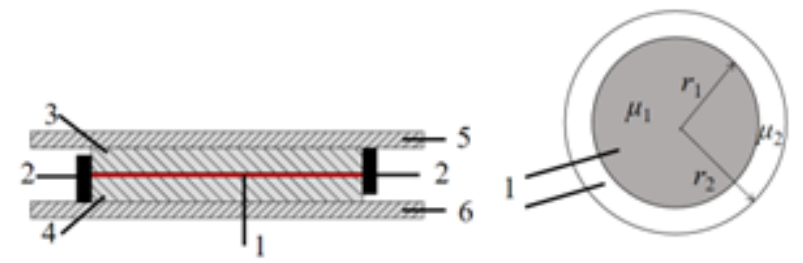

1-Sliding surface; 2-dowel; 3-Upper slider; 4-Lower slider; 5-Upper connecting plate; 6-Lower connecting plate; $\mu_{1}$-Friction coefficient of sliding surface with radius $r_{1} ; \mu_{2}$-Friction coefficient of outer annular sliding surface

\section{Figure 6}

Structural drawing of the friction sliding bearing 


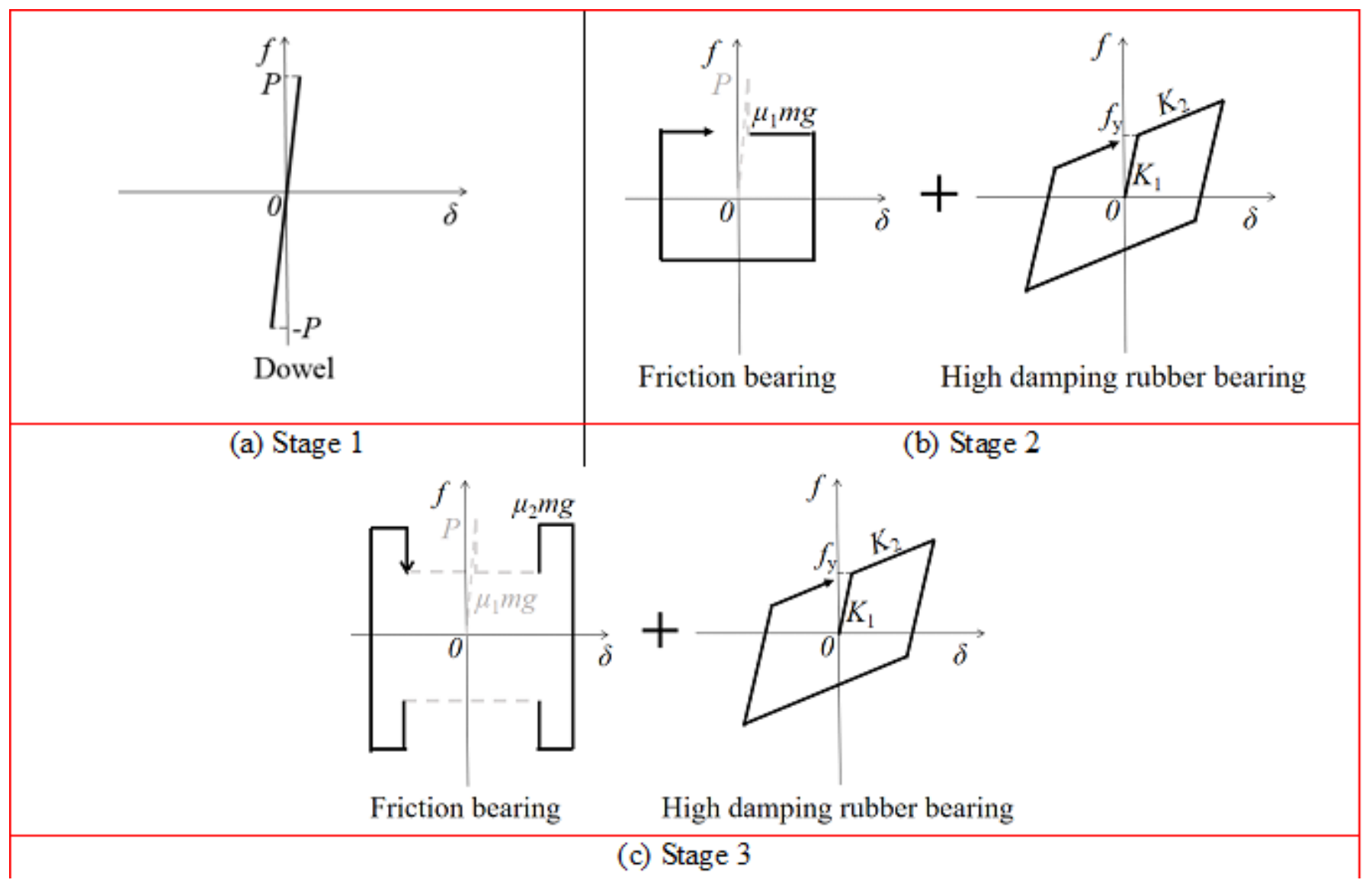

Figure 7

Hysteretic loop of the FSID

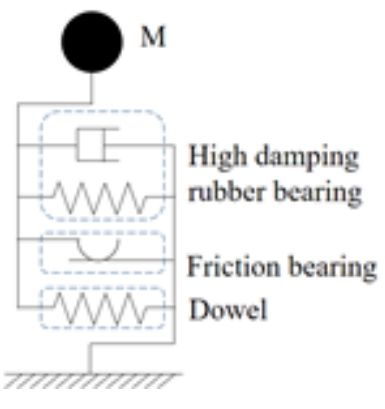

Figure 8

Analytical model 

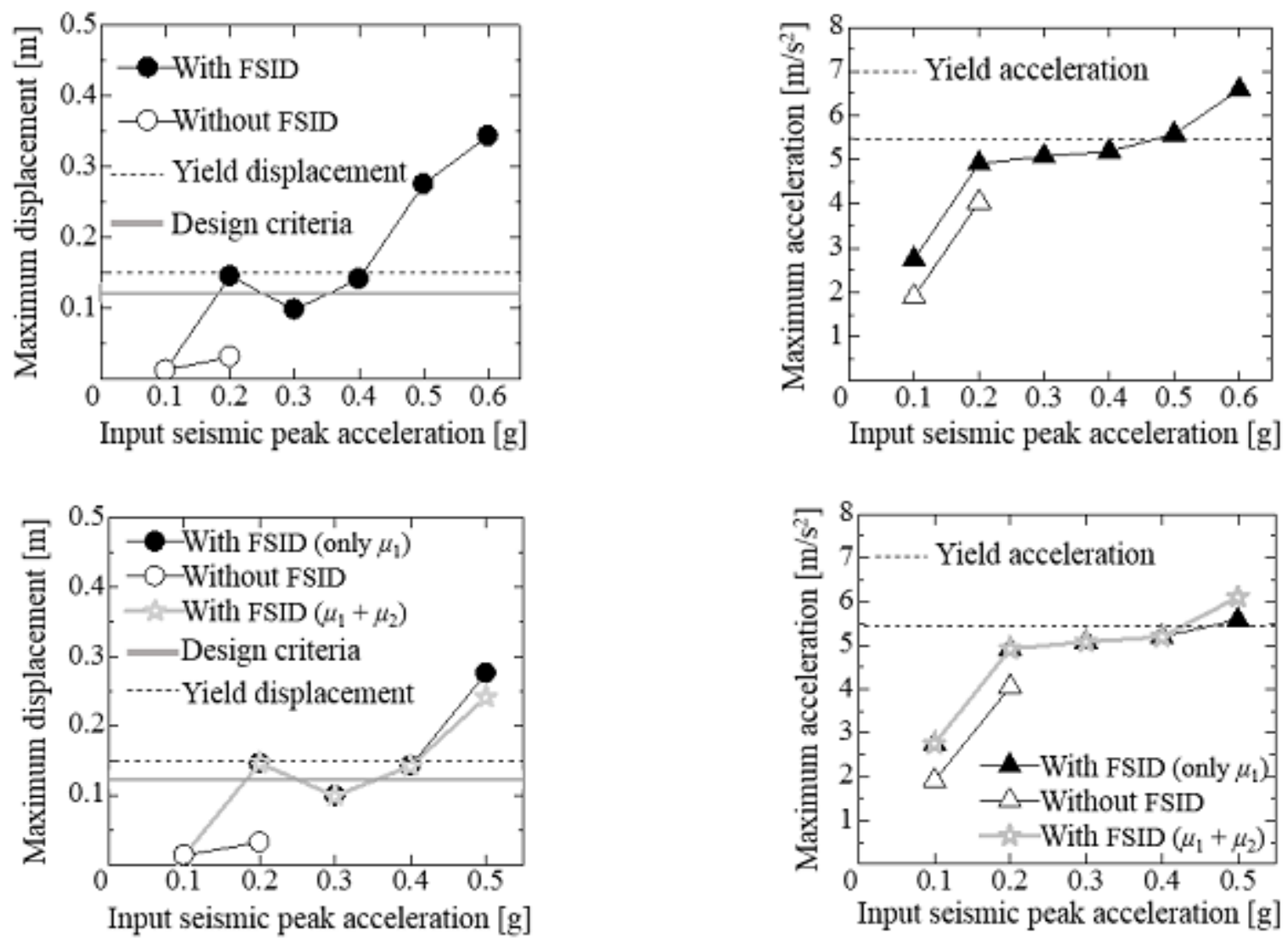

Figure 9

Maximum responses 

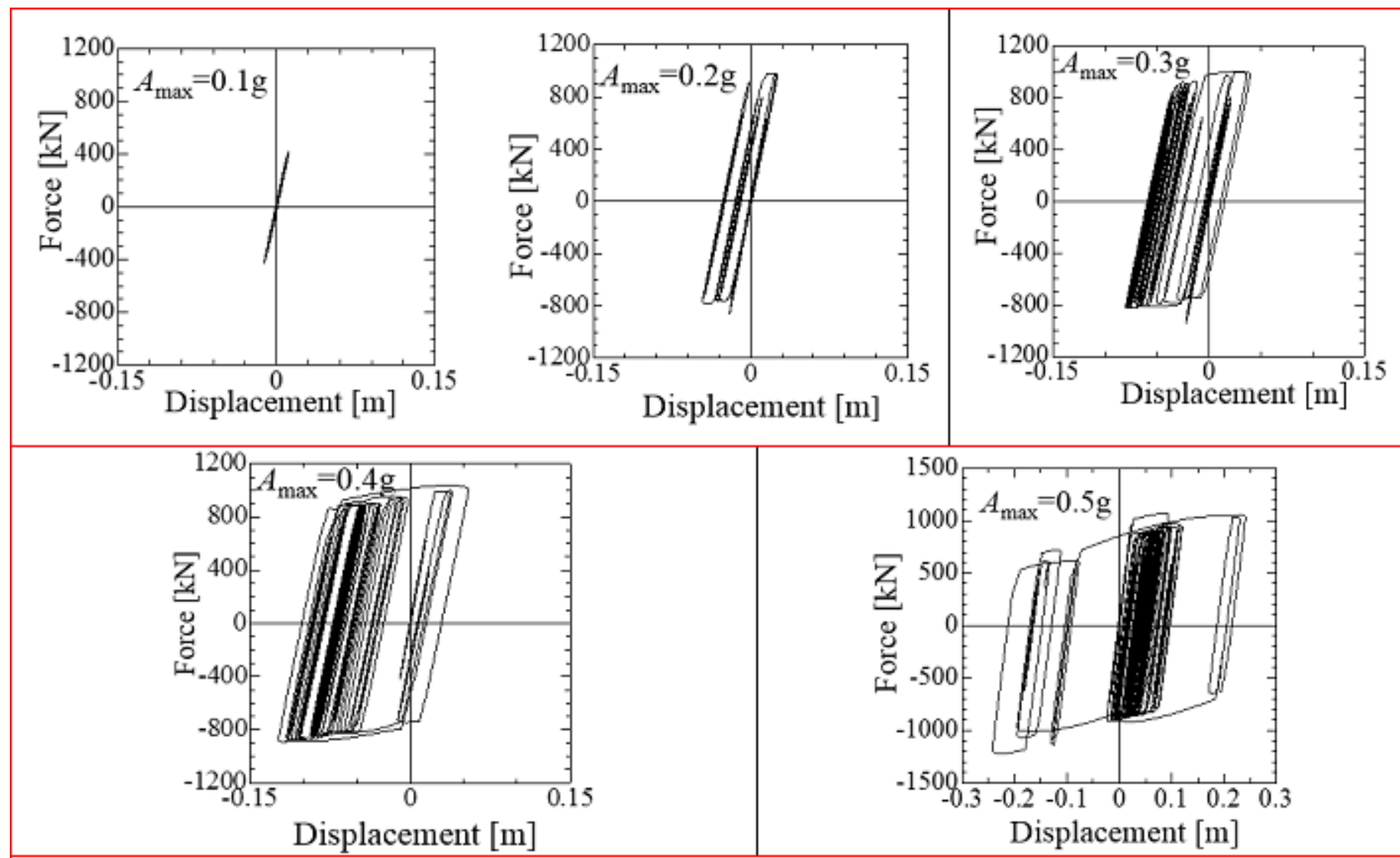

Figure 10

Hysteresis loops of the FSID under TAF-EW earthquakes
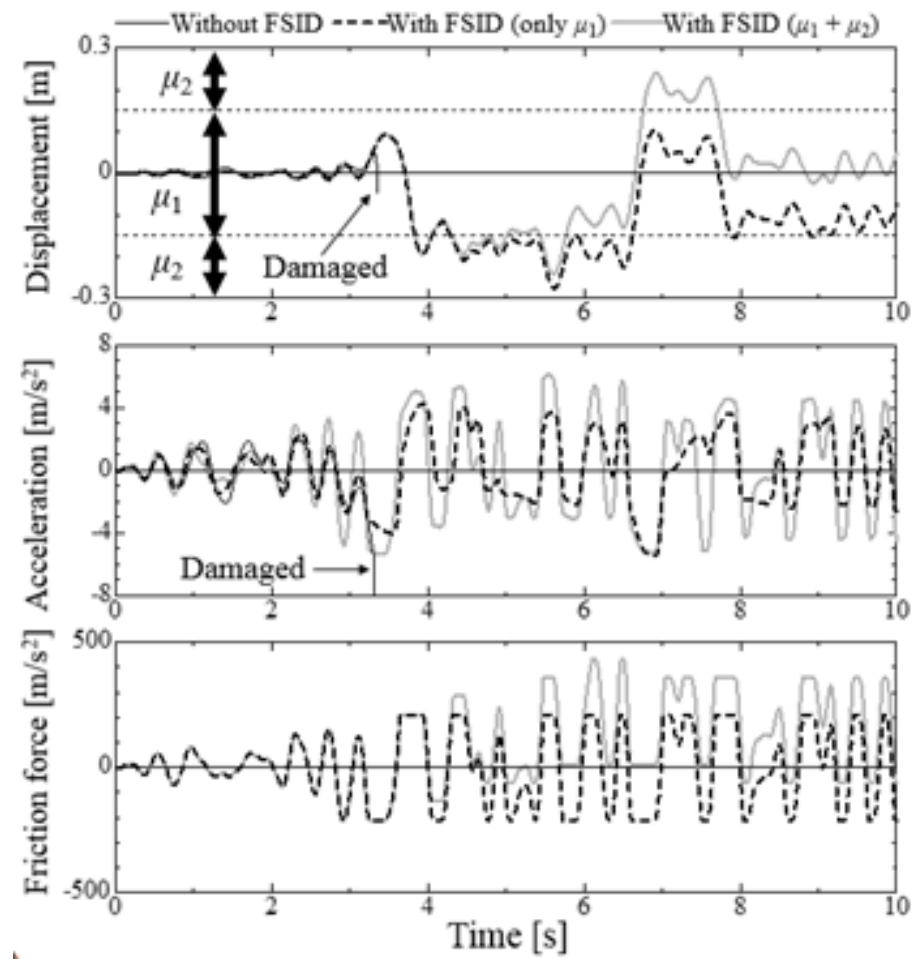

Figure 11 
Time history curves of the FSID under TAF-EW earthquakes

Page 21/21 